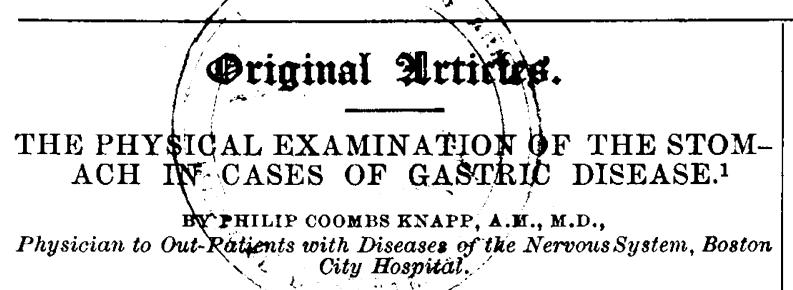

HAving had several patients with digestive disturbances under my care during the summer and fall, I sought in the first place to get a little more knowledge of what had been to me rather an obscure subject. In that way I was led to try some of the recent methods of physical diagnosis in gastric disease. The result of my reading and experience was to convince me of the value of these methods, and, although I have nothing original to offer, I have believed the subject to be of sufficient importance to justify me in presenting what is merely an abstract of the work of others.

Although the Americans are often called " a nation of dyspeptics," the diseases of the alimentary canal have formed, until lately, the most obscure chapter in medicine. We noted a history of vague symptoms - pain, distress after eating, heart-burn, nausea - we looked at the tongue and perhaps at the anus, and imagined what was going on in the twenty-five or thirty feet between. We felt of the abdomen, we regulated the bowels, and we prescribed some one of the many elegant varieties of pepsine which the manufacturers had sent us, and we knew less of the diseases of the alimentary canal than we did of the diseases of the lungs before the days of Laennec. Fortunately we have changed all that - at least in part. In no other branch of medicine, except in bacteriology, have so great advances been made as in the subject of diseases of the stomach. We have obtained the means of determining the action of that organ, and thus we have become able, not only to distinguish more clearly those affections which we formerly knew, but to differentiate other disorders whose existence was before unknown. With this increased knowledge in diagnosis has come even greater skill in treatment. We can compare the action of the diseased stomach with the normal digestive processes, and we can prescribe accurately and definitely, in accordance with the demands of the diseased organ, and not strike out blindly in a dark room with a club. This advance in our knowledge is due, of course, to the methods which have rendered a physical examination of the stomach and its functions possible, and it is to these methods that I would call your attention.

It may be well to preface my remarks with a brief review of the process of gastric digestion. When the food reaches the stomach a part of the starch has already been changed to sugar by the saliva, and may be absorbed by the stomach. It is probable that this action is kept up for a little time in the stomach until sufficient acid has been secreted, for the saliva will still act when small amounts of acid are present $(0.01$ to $0.25 \%){ }^{2}$ The fats remain unchanged. Salts and water are absorbed directly. Albumen is attacked by the gastric juice, whose active principles are hydro-chloric acid and pepsine. These dissolve the albumen, converting it into peptone, part of which is absorbed by the stomach/ while the rest passes on to

\footnotetext{
1 Read before the Suffolk District Medical Society, Section for Clinical Medicine, Pathology and Hygiene, April 11,1888.

2 Ewald. Klinik der Verdanungskrankheiten. 1886.
}

the small intestine. The solution and the passage onward are aided by the muscular movements of the stomach. With ordinary meat diet during this process lactic acid is formed ${ }^{8}$ in from ten to thirty minutes, not secreted by the gastric glands, but formed from the meat itself. This form of lactic acid (Fleischmilchsäure) or sarcolactic acid, disappears at the end of two hours, under the action, probably, of the hydro-chloric acid of the gastric juice which becomes strong enough to prevent fermentation. In disease, where abnormal processes of fermentation are going on, we may get another form of lactic acid (Gährungsmilchsäure) paralactic acid, isomerically the same, except that it polarizes to the left instead of to the right. In the gastric juice the pepsine seems to act as a pure ferment, aiding the solvent power of the hydro-chloric acid, for Petit ${ }^{4}$ has shown that it will transform one thousand times its weight of fibrine into peptone, and dissolve five hundred thousand times its weight in a few hours. After a certain time, as yet not accurately known, the peptone is more or less absorbed, the rest of the food passes on, and the stomach becomes empty.

Even if the stomach were as accessible to the touch and sight as the mouth is, it is doubtful whether we could get much information as to its diseases by looking at it, for the morbid changes in the functions of a gland are not often due to visible lesions. Of still less value, therefore, is the gastroscope devised by Miculicz. In a few instances it may give some information, but it is not safe to insert such an instrument into a diseased stomach, and the difficulty of manipulation and the cost render it impracticable for ordinary use. By the use of the ordinary soft rubber stomach-tube we can get much more accurate knowledge with much less risk.

From the physical examination of the stomach we obtain information as to the following points: (1) the time of digestion; (2) the absorbent power of the stomach; (3) the motor activity of the stomach; (4) the chemical composition of the gastric juice ; (5) the digestive powers of the gastric juice; (6) the size and position of the stomach.

(1) The time of digestion, as I have said, is not accurately known. It varies with the individual and with the character of the food taken. Leube ${ }^{5}$ has found, however, that normally, after a definite meal, all food has disappeared from the stomach at the end of seven hours. In a certain proportion of cases it may disappear before that time, but if, after seven hours, food is found in the stomach, it shows that the process of digestion is delayed. To test this, Leube orders a test breakfast - soup, a piece of beef-steak, and a slice of white bread, with water. At the end of seven hours the stomach is washed out, using about three funnels full of water, and the wash-water is examined for undigested fragments of food. In health the water should contain no such fragments.

(2) The test of the absorbent powers of the stomach is a simple one. Penzoldt ${ }^{6}$ has found that by giving a small amount of iodide of potassium (0.2 grm., gr. iij) in a gelatine capsule with a wineglassful of water at least three hours after a meal, or preferably on an empty stomach, the salt is absorbed, and can be detected in the saliva. The patient is directed

3 Ewald und Boas. Virchow's Archiv., ci., p. 325, 1885. Petit. Journal de Thérapeutique, 1880.

$\checkmark$ Leube. Deutsches A rchiv. f. klin. Med., xxxi., 1, 1883. 6 Penzoldt und Faber. Berlin. kl. Wochenschrift. 22 May, 1882. 
to spit once a minute on a bit of starch paper, which hydro-chloric. If abnormal processes of fermentation is then touched with a drop of fuming nitric acid. In are going on there may also be lactic, butyric, or health, in from seven to fifteen minutes, there is found acetic acids. The presence or absence of hydro-chlofirst a reddening and then a bluing of the paper.

(3) The test of the motor activity of the stomach is equally simple. Ewald ${ }^{7}$ has lately found that salol is changed in an alkaline solution to salicylic acid. The acid gastric juice has no effect on it, but when it passes through the stomach, it is changed to salicylic acid by the alkaline pancreatic juice, absorbed, and eliminated by the urine. The patient is given three to five grains of salol, and specimens of the urine obtained every fifteen minutes or half an hour. The addition of a drop of tincture ferri chloride to the urine will, when it contains salicylic acid, give a deep brownish-red color. This color is said to be found in from half an hour to an hour, after taking salol. If it does not appear until after that time, the motor activity of the stomach is regarded as below normal. Later observers make the time rather longer.

(4) The methods of obtaining the gastric juice, and of testing its chemical composition, have been the subject of much controversy, and the question is by no means settled yet. Leube ${ }^{8}$ suggested three methods of obtaining the juice. The first was by the mechanically irritation of the mucous membrane of the stomach by means of a stiff sound, which naturally proved impracticable. The second was to wash out the stomach with 400 cc. of luke-warm water; then introduce $50 \mathrm{cc}$. of a three per cent. soda solution, letting it stay twelve minutes, and then adding $500 \mathrm{cc}$. of luke-warm water, siphoning out, and testing the acidity ; alkalinity of the wash-water showing insufficient acid. The third, which was the one he generally employs, is to wash out the stomach, introduce $100 \mathrm{cc}$. of iced water, letting it stay ten minutes, and washing it out with 300 cc. of water.

Jaworski and Gluzinski ${ }^{9}$ obtain the juice by giving the patient the whites of two eggs, hard-boiled, and $100 \mathrm{cc}$. of distilled water, at a temperature of $18^{\circ} \mathrm{C}$., $\left(65^{\circ} \mathrm{F}.\right)$. The patient sits still an hour and a quarter and then the stomach is washed out with 100 to 300 cc. of water. By that time the egg should be digested, and the diluted juice may be tested.

The trouble with these methods is that they give a juice much diluted with water, and therefore estimates as to the acidity or the digestive power of the juice, must make allowance for this dilution. Riegel ${ }^{10}$ has therefore sought to obtain the juice in an undiluted form. To this end he passes the stomach-tube during the period of active digestion, two or three hours after a hearty meal, and expresses a part of the contents of the stomach through it. This is filtered, and the filtrates contain the undiluted juice mixed with peptones. The residue, if desired, may be examined microscopically for sarcinæ, bacteria, etc.

Ewald ${ }^{11}$ has suggested a modification, giving two rolls, weighing from 30 to 35 grammes, and a cup of green tea without milk or sugar. An hour later he expresses a part of the contents of the stomach in the same way.

As I have said above, at the end of two hours, after a mixed meal, the only acid in the stomach should be

7 Ewald. Wiener Med. Press. July 10, 1887.

8 Leube. Art. cit.

Jaworski und Gluzinski. Zeitsehr. f. klin, Med., xi, 50, 270, 1886. 10 Riegel. Deutsches. Archiv. f. klin. Med., xxxi, 100, 1885. Zeitschr. f. klin. Med., xi, 167, 1886; xii, 426, 1887. Volkmann's klin. Vorträge, No. 289, 1886.

11 Ewald. Berlin. kl. Wochensohr. Jan. 18, 25, 1886. ric acid is therefore the important point. Unfortunately, if any of the organic acids be present, they may respond to some of the tests, and much work has been done to find tests that will show even minute traces of hydro-chloric acid, without re-acting to the organic acids.

First of all, the question of the acidity of the juice should be determined by the use of Congo-red paper, which turns blue when acid is applied. It is rather more delicate than litmus, but the latter should be used as a control.

Then to a little of a concentrated solution of tropæolin (that known to the trade as Merck's 00) spread out on a porcelain dish a drop of juice should be added. If the juice contain hydro-chloric acid it produces first a lilac red and soon a smutty brown color. This change, however, may be produced by a $2: 1000$ solution of lactic acid (Uffelmann)..$^{12}$

The test in common use is that with methyl aniline violet. If to a rather dilute aqueous solution of methyl violet a drop or two of gastric juice containing hydrochloric acid be added, the color changes to blue.

Ewald and Boas ${ }^{18}$ and Uffelmann, make more or less use of Mohr's test. This consists in adding a couple of drops of juice to a layer of the following mixture :

$$
\begin{aligned}
& \text { Liquor ferri acetici (C. P.) } \\
& 10 \% \text { sol, potass. sulpho-cyanide } \\
& \text { Aqua dist. } \\
& \text { M }
\end{aligned}
$$

This forms a clear ruby-red solution. If hydrochloric acid be added it turns violet, and later a mahogany brown.

Rhode's ${ }^{14}$ test consists of equal parts of a half per cent solution of ammonic sulpho-cyanide and a fresh solution of tartrate of sodium and iron oxide, which becomes brown-red with dilute solutions $(0.25$ per cent.) of hydro-chloric acid.

Von den Velden ${ }^{15}$ recommends a solution of fuchsine (rosaniline chloride) which loses its red color with hydro-chloric acid.

Uffelmann ${ }^{16}$ is a strong advocate of two tests. The first is by use of the coloring matter of red Bordeaux wine. The wine must respond to various tests, for which I will refer to his original paper. One cc. of this wine is shaken with three cc. of absolute alcohol and filtered. He then wets paper with this filtrate, dries it in a cool place, and uses it like litmus. Hydrochloric acid changes it from a bluish-red to a rosy red. His other test is a paper soaked in the juice of huckleberries which is turned red by hydro-chloric acid.

Von Jaksch ${ }^{17}$ quotes Voigt as recommeuding a solution of emerald green (the "krystallisirt" of B. Bayer), which is changed to a grass or yellow green by dilute hydro-chloric acid, while organic acids have no effect, and mentions several similar colors which are less sensitive.

Cahn and v. Mering ${ }^{18}$ have devised a very elaborate method of determining the presence of hydrochloric acid, even in minute quantities, by distillation 12 Uffelmann. Deutsches Archiv, f. klin. Med., xxvi, 431, 1880. 13 Ewald und Boas. Art. cit.

14 Quoted by Ewald. Op. eit.

15 Von den Velden. Deutsches Archiv. f. klin. Med., xxiii, 369, 1878. 16 Utfelmann. Zeitschrift f.klin. Med., viii, 392, 1884 .

17 V.Jaksoh. Klinische Diagnostik. 1887.

18 Cahn und v. Mering. Deutches Archiv. f. klin. Med., xxxix, 233,
1886. 
and digestion with cinchonine, but it is too complicated for ordinary clinical use, so I will not describe it here, although I shall refer to the conclusions which they draw from it later.

Finally, I will mention a new test described by Günzburg, ${ }^{19}$ which I learn from Dr. J. W. Warren is very trustworthy and satisfactory. He uses the following solution:

$$
\begin{aligned}
& \text { Phloroglucin (Merck's) • • • • • • • } 2.0 \\
& \text { Alcohol (absolute) } \quad: \quad: \quad: \quad: \quad: \quad: \quad: \quad 30.0
\end{aligned}
$$

This gives a yellow-red solution. If a few drops of this be added to an equal amount of gastric juice containing hydro-chloric acid and gently warmed on a porcelain plate, deep-red crystals are formed. This solution reacts to very small amounts of hydro-chloric acid, 0.01 per cent. and less, and does not react, even to concentrated organic acids. Dr. Warren regards it as the only satisfactory test.

The presence of pepsine is to be determined by a digestive experiment. The detection of peptones is not very important. The test is simple, however, and is the ordinary biuret reaction. The solution is diluted, rendered alkaline by sodic hydrate, and a few drops of a dilute solution of cupric sulphate are added. If peptones be present, the solution turns a rosy red, but if albumen be present alone, it turns violet. (Sticker.) ${ }^{20}$

The test for the acids found where there is fermentation is much simpler, or rather all authorities agree. Uffelmann ${ }^{21}$ has proposed a test for lactic acid which is generally accepted. He takes one or two cc. of the following solution:

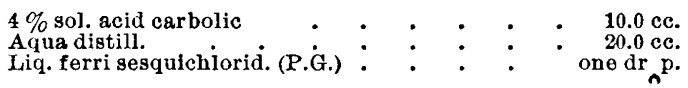

This forms a steel-blue solution, which is decolorized by hydro-chloric acid, and turned yellow by lactic acid.

If the juice be shaken with ether, and the ethereal residue evaporated, acetic and butyric acids can be detected by the smell. On neutralizing the ethereal solution with sodic carbonate and adding the iron solution, acetic acid will turn it blood-red. On adding distilled water, a drop or two, and a bit of calcic chloride, oil drops of butyric acid will appear on the surface. These tests, however, are unimportant.

Having determined the presence or absence of hydro-chloric acid, the juice should next be subjected to a quantitative determination of the acids. Uffelmann gives the following approximate tests:

Huckleberry juice shows - • - $0.024 \%$ hydro-chlorio acid.

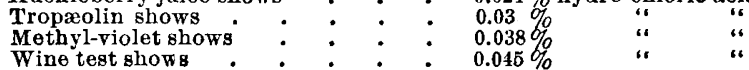

Von den Velden ${ }^{22}$ thinks the normal amount of hydro-chloric acid is $0.12 \%$. Ewald ${ }^{28}$ thinks the normal limit varies between $0.15 \%$ and $0.4 \%$, with the normal average of $0.2 \%$, and other observers think that a percentage above 0.25 or 0.3 is to be regarded as suspicious. For an accurate test, only a small amount ( $\frac{1}{2}$ to 1 cc.) of the juice is necessary. This is diluted with a weak solution of phenol-phthalein, and the decinormal sodic hydrate solution is run into it from a burette until a red color persists. The amount of acid is then easily calculated, as the decinormal

19 Günzburg. Centralbl.f. klin. Med. Oct. 1, 1887.

20 Siticker. Deutsche Med. Zeitung. Feb. 28, 1887.

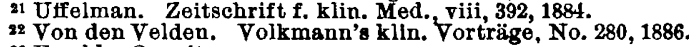

22 Von den Velden.
23 Exald. Op. cit. sodic hydrate solution contains $4 \mathrm{mgr}$. to the cubic centimeter.

(5) As I said before, the presence of a sufficient amount of pepsine is best shown by testing the digestive power of the stomach. The test is very simple: A bit of egg-albumen is put into a test-tube containing 10 to 20 cc. of the juice, and kept at the temperature of the body. For this purpose, it is well always to take a piece of the same size. Sticker ${ }^{24}$ advises a disc $8 \mathrm{~mm}$. across and $1 \frac{1}{2} \mathrm{~mm}$. thick. I have used a bit measuring $8 \times 4 \times 1 \mathrm{~mm}$. If the juice be undiluted, this should be digested in from two to three hours. With diluted juice, the time, of course, will vary. If juice enough be obtained, it is well to perform control experiments at the same time by taking three test-tubes and leaving one untouched, adding a drop of dilute hydro-chloric acid to the second, and a flake of pepsine to the third.

(6) The determination of the size and position of the stomach is of importance chiefly in cases of suspected dilatation, and various methods have been de. vised for this purpose. Palpation and percussion may furnish some slight aid, but, as a rule, other methods are necessary. Leube ${ }^{25}$ passed a stiff sound into the stomach, and endeavored to feel the point through the abdominal wall. but this procedure is not easy in stout patients, and is full of danger. Penzoldt ${ }^{26}$ had the patient take considerable water, and thus mapped out the lower border of the stomach by detecting the dulness. Schreiber ${ }^{27}$ tied a rubber balloon to the end of the stomach-tube, and thus inflated the stomach. Neubauer ${ }^{28}$ and Fleischer ${ }^{29}$ determined the level of the liquid in the stomach by connecting the stomach-tube with a U-tube outside the body. Rosenbach ${ }^{30}$ put water in the stomach, passed a tube into the water, and then, ausculting over the abdomen while he pumped air into the stomach, determined, by listening to the bubbles rising through the water, the upper level of the fluid. Kussmaul ${ }^{81}$ inflates the stomach by generating gas within. For this purpose, he gives $2 \mathrm{grm}$. of bicarbonate of soda and $1 \frac{1}{2} \mathrm{grm}$. of tartaric acid, and the size of the stomach when filled with the gas thus generated can readily be determined by palpation and percussion. In using this method, a stomach-tube should be in readiness in case unpleasant symptoms should arise from over-distension. Purgesz: ${ }^{82}$ taking the average distance from the incisors to the cardiac orifice, finds how much farther the sound can be pushed downwards - a method applicable only with the stiff sound, and liable to the same objections as Leube's method.

Having spoken at length of the various methods recommended, before speaking of the conclusions to be drawn for diagnosis from these tests, I will briefly describe the methods of procedure which I have selected as best adapted for use for clinical purposes substantially those of Riegel.

The patient's history should first be taken, and, if there is recent history of hæmatemesis, the tube should not be used. The abdomen should be carefully examined, inspected, palpated, percussed, and ausculted. The chest should also be examined, for a Sticker. Art. cit.

28 Loube. Die Magensonde, 1879

${ }^{26}$ Penzoldt. Die Magenerweiterangen, 1875

${ }^{27}$ Schreiber. Deutsches Archiv f. klin. Med., xxix.

${ }^{28}$ Neubauer. Prager Med. Wochenschr., No., 14, 1878.

99 Fleischer. Ref. Leube. Op. cit.

${ }^{30}$ Rosenbach. Volkmann's Klin. Vorträge, No. 153, 1879.

s2 Kussmaul. Volkmann's Klin. Vorträge, No. 181, 1880. 
the tube should not be used if there is a thoracic aneurism. Leube recommends a tube of $11 \mathrm{~mm}$. diameter (33 French), with a calibre of $7 \mathrm{~mm}$., but a smaller one will answer - my own is about $9 \mathrm{~mm}$. (25 French). The patient should sit erect, the head thrown a little back, the mouth well open, and the tongue may be depressed and pulled forward a little by a spatula or the left index finger. The tube is then passed into the fauces, past the epiglottis, and into the pharynx. Once engaged in the osophagus, there is no further trouble, except that it may stick for a moment at the cardiac orifice. If it does, a little water poured into the tube will overcome this obstacle. If the patient begins to retch or to show signs of suffocation, he should be told to take deep breaths. It is rarely necessary to withdraw the tube. It is certainly not easy to get a tube into the larynx of a sane man. If cocaine be used - and it makes the process easier such an accident may be possible, although $I$ doubt it. It is well to wait a moment, however, to see if the patient breathes naturally. When the tube reaches the stomach, it generally happens, unless the stomach be quite empty, that we hear a bubble or two of air come up the tube - a point mentioned at a meeting of the Section a year or two ago by Dr. Boland. have found that milk is a good material to lubricate the tube with to facilitate the introduction, being much less nauseating than vaseline or oil. To wash out the stomach, a piece of rubber tubing is connected with the stomach-tube, with a funnel at the end, and about a pint of warm water is slowly poured into the funnel, holding the funnel end well up. By suddenly lowering the funnel, the contents of the stomach may thus be siphoned out. In withdrawing the tube, care must be taken to compress the end tightly before withdrawal, so that the contents of the tube may not drop into the larynx. If the tube be passed through the nostril - the favorite way of introduction when it is used for feeding the insane - the patient may lie down. In the cases that I have tried, it seems less disagreeable to the patient to pass it through the nose, but as I never tried both methods on the same patient, it is hard to make comparisons. Patients sometimes get so used to the passage of the tube that they will swallow it down themselves. The dangers of the procedure are slight, less than those of catheterizing the bladder. The chief risk, of course, is of passing the tube into the trachea and setting up an inhalation pneumonia, but this is not great, except among the insane. Slight traces of blood are of no account. One patient reported to me raising half a teacupful of "blood and corruption" after the first passage of the tube, but it seemed to do no harm. It might be well to tie a string to the tube, for in a case reported the whole tube was swallowed.

Having taken the patient's history, and made a careful external examination, I prefer first to get a specimen of the gastric juice. This I do by expression by Riegel's method, having the pationt come to me about three hours after a meal. Having passed the tube, external pressure over the abdomen, or a voluntary effort on the part of the patient, will generally press out a certain portion of the contents of the stomach. Having filtered it, I test the acidity of the filtrate by litmus and Congo papers, and then I have thus far tested for free hydrochloric acid with tropæolin and methyl violet. Hereafter I shall use Günzburg's test. I then test for lactic acid with Uf- felmann's reagent, reserve about 1 cc. of the juice for a quantitative test, and, if there is enough, divide the rest of the juice into three parts to test its digestive power. All this requires only about an ounce of gastric juice. If abnormal fermentation is suspected, I shake with ether, and smell the residue to detect butyric or acetic acid. The next day, or later, I prescribe Leube's test breakfast - soup, steak and bread - taking care to measure the size of the steak and bread taken, and the quantity of soup. Seven hour's later I wash out the stomach, taking care that the patient eats nothing between whiles. During one of the visits Penzoldt's test for absorption may be made, and between them the patient may be given a dose of salol with instructions to save several specimens of urine passed every half-hour after taking it. For determining the size of the stomach Penzoldt's fluid test is the simplest, but, if it prove unsatisfactory, it may be supplemented by Kussmaul's test.

What do we learn from all this? What is the good of such an examination, which seems so elaborate, yet which is really comparatively simple - less difficult, except as far as obtaining the juice, than a thorough examination of the urine? By it, as I said at the beginning, our knowledge of diseases of the stomach has been put on a firm foundation. I am so fully convinced of the value of these methods that $I$ am ready to say that a man who tries to treat a serious and obscure case of gastric disturbance without resorting to them, is as guilty of negligence as the man who tries to treat an obscure case of thoracic disease without using the stethoscope.

The most important question refers to the presence or absence of free hydro-chloric acid in the gastric juice. The weight of evidence is decidedly in favor of the opinion that in cancer of the stomach there is no free hydro-chloric acid in the gastric juice. The chief authority opposing this view is that of Cahn and von Mering, who, by the method spoken of above, have found acid in cancer. Rosenbach ${ }^{88}$ alone claims to have found hydro-chloric acid in cancer by the ordinary tests. The experiments of Cahn and von Mering, however, have recently been repeated by Honigmann and v. Noorden, ${ }^{84}$ who believe that the juice in cancer does not contain the free acid, but acid combined with unstable albumen derivatives, which are broken up by the method employed. If, then, the gastric juice constantly reacts to the ordinary tests with tropæoline and methyl violet, it is safe to say that there is not cancer. The absence of hydro-chloric acid, however, is not pathognomonic of cancer, for it has also been found absent in atrophy of the stomach and in the backward flow of bile (Riegel), ${ }^{85}$ in amyloid disease of the stomach, and temporarily in catarrh, from increase of mucus, and in febrile diseases (Edinger).$^{86}$ In such cases the time of digestion is, of course, prolonged, and the digestive power of the juice is impaired, even if hydro-chloric acid is added, showing that there is a decreased amount of pepsine.

In contradistinction to the cases where hydrochloric acid is absent come those where it is increased, or where there is a continuous secretion of gastric juice (Reichmann, ${ }^{87}$ Riegel.) ${ }^{88}$ This condition gives rise

88 Rosenbach. Centralblatt f. klin. Med. 6 Aug., 1887.

st Honigmann und v. Noorden. Zeitschr. f. kilin. Med. xiii., 87, 887.

${ }_{38}$ Riegel. Arts cit.

36 Edinger. Berlin. klin. Wochenschr., 1 March, 1880

st Reichmann Berlin. klin. Wochenschr., 2 Oot. 1882

ss Riegel. Deutsche Med. Wochenschr., 31 July, 1887. 
to thirst, heart-burn, pain at night, and acid vomiting. The stomach must be washed out at night, and then the tube passed before breakfast the next morning. In these cases the stomach is found to contain 180 to $300 \mathrm{cc}$. of an acid fluid, which digests albumen, and gives the reactions for hydro-chloric acid. This is the only pathognomonic test for this condition. The amount of acid may also be increased to $0.3 \%$ and over. ${ }^{89}$ Riegel ${ }^{40}$ believes this condition to be quite common. It is of especial interest as pointing to a possible cause of ulcer, the extreme acidity of the juice rendering selfdigestion easier. Some of the symptoms are like those of ulcer, and in ulcer there is usually an extreme acidity of the juice."

The detection of other acids points to abnormal processes of fermentation going on in the stomach, as in catarrh or dilatation of the stomach. The significance of the digestive test has been mentioned in connection with the absence of hydro-chloric acid. The tests for absorption and muscular activity have been too little studied as yet. The muscular activity would naturally be diminished in dilatation, where the methods for determining the size of the stomach are also called for. When there is digestive disturbance, but the stomach digests a test breakfast in seven hours, and the juice is normal, the condition is often spoken of as " nervous dyspepsia." ${ }^{42}$ Many cases are undoubtedly due to some nervous disorder, while in others the absorbent power and the muscular activity of the stomach have not been carefully tested. Where there are other signs of a neurotic condition the term may be used, but at best it is vague, and in many cases we can define the numerous nervous affections of the stomach more exactly.

What do these new methods teach us in regard to treatment? Enough to cause us to alter our present methods. In the majority of cases there is a normal or excessive amount of hydro-chloric acid, hence the common exhibition of it is needless, and often injurious. Where the acid is in excess we should not depend on alkalies. The stomach should be washed out at night, Carlsbad water given in the morning, and the stomach given increased work by giving the patient an albuminous diet, avoiding carbohydrates. When acid is absent, or much diminished, the ordinary dose $\left(\eta_{v-x}\right)$ is much too small. Ewald ${ }^{48}$ has calculated that to render neutral juice properly acid, thirty to forty-five minims should be given after each meal, in three doses fifteen minutes apart, beginning about an hour after meals. When acidity of the stomach is due to lactic acid, from fermentation, this should not be combatted solely by alkalies, although Carlsbad may be used. The stomach should be washed out, and hydro-chloric acid given, for it will be remembered that when hydro-chloric acid is formed during digestion it checks the formation of lactic acid. In catarrh and dilatation washing out the stomach is a remedy to be first employed. In muscular insufficiency strychnine and very mild faradic currents may prove serviceable. In "nervous dyspepsia," as I have long believed, special treatment is uncalled for; we must build up the nervous system, and the stomach will take care of itself.

${ }^{89}$ Von den Velden. Volkmann's klln. Vorträge, No. 280, 1886.

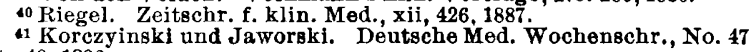
to 49,1886 .

${ }_{42}$ Leube and Ewald. Verhandl. d. Congress. d. inner. med., iii., $204,1884$.

${ }^{4}$ Ewald. Berlin. klin., Wochenschr., No. 3, 4, 1886.
I have said nothing of that panacea for all disturbances of digestion, of which at least nineteen varieties are brought to our attention weekly, namely, pepsine. I have always acted on the statements which the physiologists have been making for years, that pepsine is required for digestion only in small amounts, and that hydro-chloric acid was the important factor. In the great majority of cases there is plenty of pepsine in the gastric juice, and the addition of any more is needless, and therefore wrong. In a few instances where partly digested food is to be given, pepsine becomes necessary in its preparation, otherwise the use of pepsine is thoroughly unscientific.

I have dwelt chiefly upon the methods of research, referring briefly and cursorily to these points where they throw light on the diagnosis and treatment. The thorough examination is not agreeable to the patient, although it is not dangerous, and it takes a certitin amount of time and trouble. I can merely repcat that the more I try it the more firmly I am convinced of its value and necessity, and I fully agree with Ewald's dictum." "I grow more convinced daily that an exact diagnosis of gastric diseases, and a sound treatment based on it can be obtained only by a careful chemical examination of the gastric juice or the gastric contents by the methods of qualitative and quantitative determination of acids as given above."

\section{AN EXERCISE IN THE EXTEMPORIZATION OF LITTERS FROM RIFLES AND GUNSLINGS.}

BY JAMES E. PILCHER, M.D., PH.D. Assistant Surgeon in the United States Army.

For a number of years past, the subject of the conveyance of the disabled as an important part of early aid in accidents and emergencies, has been a popular one. The St. John's Ambulance Association in England, the Samaritan Societies in Germany, and still other bodies in other countries, all serving under the Red Cross, have contributed to this end. Foreign armies have long possessed thoroughly organized corps devoted to this work, and now the National Guard of many of our States is provided with an ambulance corps, while the regular army, with its hospital corps supplemented by four "company bearers" from each company, troop, and battery, has a foundation upon which is being erected a system of "first aid" that will be a material advance upon the work already done. In a recent lecture before the Military Service Institution, the writer presented some of the results of a considerable number of experiments as to the best methods of conveying the disabled by human bearers. The well-known method of carrying the disabled upon a litter extemporized from two rifles and their gunslings was particularly pleasing to many, and a strong desire has since been expressed for a system of movements by which such a litter could be constructed with the least confusion and delay.

In deference to this desire, the following exercise has been devised. Unless otherwise specified, the movements are to be executed in accordance with the authorized United States Infantry tactics :

The bearer company or squad being formed in two ranks, with their pieces at "carry arms," the medical officer commands, (1) Rear open order, (2) MARCH, which is performed in the usual manner. He then

«t Ewald. Klinik der Verdanungskrankheiten, I, 107, 1886. 